\title{
Hitting the Bullseye: Are Cell Penetrating Peptides (CPP) the Future of Targeted Cancer Therapy?
}

\author{
Edward AF Polglase ${ }^{1}$, Diana E Shroff ${ }^{2}$ and Keith S Robinson ${ }^{3 *}$ \\ ${ }^{1}$ Department of Life Sciences, Imperial College London, UK \\ ${ }^{2}$ Department of Medicine, Imperial College London, UK \\ ${ }^{3}$ Department of Scientific Innovation, UK \\ *Corresponding author: Keith S Robinson, Department of Scientific Innovation, MicroQuin, London, UK
}

Submission: 每 September 03, 2018; Published: 每 September 06, 2018

\section{Introduction}

Cancer treatments have traditionally entailed system wide toxicity with debilitating side effects for the patient. The demand for targeted therapies is clearly exhibited in the pipeline of large pharmaceuticals where the need to identify delivery vehicles that offer the prospects of more targeted, efficacious treatments with fewer side effects is paramount. Historically a number of technologies have been tried and tested including antibody drug conjugates, nanoparticles, cell surface markers and targeting the tumor microenvironment. Unfortunately, these approaches have often had lackluster results and created alternative toxic profiles, such as immune activation. Interest in an historic technology, cell penetrating peptides (CPPs), has been recently reinvigorated, presenting the opportunity to deliver targeted, biologically active cargoes to cancerous cells for treatment without systemic side effects.

\section{CPP Classification and Method of Internalization}

A brief history of the CPP is summarized in Table 1 CPPs typically comprise of 5-30 amino acids and can pass through tissue and cell membranes via energy-dependent or -independent mechanisms. CPPs can be broadly grouped, based upon their physicochemical properties [1-7], into cationic (e.g. TAT49-57, penetratin and poly-arginines), amphipathic (e.g. Pep1, MPG, MAP, transportin) or hydrophobic (e.g. C105Y, PFVLYI, Pep-7) [8]. Functionally, irrespective of their categorization they act as transport agents to deliver biologically active conjugates (cargoes) including proteins, peptides, DNAs, siRNAs and small drugs into specific cells/tissues. Cargoes are conjugated to CPPs either by covalent bonds or non-covalent complex formation. Covalent coupling is commonly via chemical linkage, usually via disulfide or thioester bonds, or recombinant protein creation and expression. However, covalent coupling does risk altering the biological activity of the conjugate; therefore, it is commonly more appropriate to utilize a non-covalent strategy when conjugating cargo to the CPP [9]. The advantages of non-covalent linkage include decreased likelihood of steric hindrance of the cargo and increased serum half-life of cargoes by protection against protease or nuclease degradation.

Table 1: Summary of the key developments in CPP history.

\begin{tabular}{|c|c|c|c|}
\hline Year & $\begin{array}{c}\text { Notable Developments in } \\
\text { CPP History }\end{array}$ & Group & $\begin{array}{l}\text { Refer- } \\
\text { ence }\end{array}$ \\
\hline 1988 & $\begin{array}{l}\text { HIV-1 TAT protein -the first } \\
\text { CPP is discovered }\end{array}$ & $\begin{array}{l}\text { Frankel \& Pabo } \\
\text { [1] and Green \& } \\
\text { Loewenstein [2] }\end{array}$ & {$[1,2]$} \\
\hline 1991 & $\begin{array}{l}\text { pAnt - a cell penetrating } \\
\text { homeodomain within An- } \\
\text { tennapedia was identified }\end{array}$ & Joliot et al. [3] & [3] \\
\hline 1994 & $\begin{array}{l}16 \text { critical residues within } \\
\text { pAnt's third helix were } \\
\text { identified and synthesised, } \\
\text { creating the CPP, penetra- } \\
\text { tin. }\end{array}$ & Derossi et al. [4] & [4] \\
\hline 1994 & $\begin{array}{l}\text { Researchers utilise proteins } \\
\text { such as beta-galactosidase } \\
\text { to confirm Tat's ability to } \\
\text { internalise cargoes }\end{array}$ & Fawell et al. [5] & [5] \\
\hline 1997 & $\begin{array}{l}\text { The sequence essential } \\
\text { to Tat internalisation was } \\
\text { identified as Tat } 48-60\end{array}$ & Vivés et al. [6] & [6] \\
\hline 2002 & $\begin{array}{l}\text { Further Tat sequence } \\
\text { optimisation produces the } \\
\text { truncated Tat } 49-57\end{array}$ & Park et al. [7] & [7] \\
\hline 2003 & $\begin{array}{l}\text { First clinical trial utilising } \\
\text { CPPs }\end{array}$ & $\begin{array}{l}\text { Cell Gate, Inc. Gui- } \\
\text { dotti G et al. [8] }\end{array}$ & [8] \\
\hline
\end{tabular}

In the last 10 years, there has been a surge in discovering amphipathic CPP technology. It is our opinion that this is because amphipathic CPPs have exhibited an increased targeted nature to a specific cell type/tissue, with increased penetrative properties to deliver cargo. When assessing the physio- and biochemical properties of amphipathic CPPs, is seemingly an increased likelihood of these being derived from metalloproteins or bacterially derived periplasmic binding proteins which bind positive charged ions i.e. 
Zn, Ca. This observation could benefit future CPP 'mining' exercises as bioinformatics begins to play a more pivotal role in scientific discovery [10].

To date, several methods of CPP internalization have been identified and can be broadly categorized into direct penetration (e.g. pore formation, inverted micelle, carpet model) or via endocytic models (e.g. endocytosis or micropinocytosis). Direct internalization involves the CPP forming close interactions with the membrane itself, unlike endocytic models, which rely on the specific (i.e. caveolin, clathrin) or non-specific (macropinocytosis) engulfment of compounds following membrane remodeling [11].

\section{Identifying CPPs}

To date, identification of a CPP with the required physiochemical and biochemical properties, to uniquely target a specific cell type and deliver a cargo, has been somewhat serendipitous. However, modern bioinformatics is becoming increasingly powerful and is able to tentatively deduce protein structures. Nevertheless, we are still a long way from be able to fully rely on this tool to wholly identify or design a CPP that targets a unique cell type of our choosing.

In the 30 years since CPPs initial discovery, a number of preclinical and clinical studies have been carried out. Their use has been in treating neurodegenerative disease as well as myocardial infarction, inflammation and oncology. The first clinical trial involving CPPs was carried out by Cell Gate in 2003, utilizing a polyarginine CPP conjugated to Cyclosporin A for the treatment of Psoriasis. The technology made it to Phase II, but the trial was discontinued due to the rate of clearance being greater than free drug release [6].

Currently there are various CPPs at differing stages of clinical development primarily focused on oncology treatment. CDG Therapeutics (Phase II clinical trials) with their compound NSC745104 investigated Safety, Tolerability, PK and preliminary activity of patients with p53(+) metastatic solid tumors in Phase I. No patients exhibited any dose-limiting toxicity, significant adverse events or exhibited an immune response to the peptide; and the anti-tumor activity indicated a highly favorable therapeutic index. Furthermore, they tested this on pediatric brain tumor gliomas, gathering such positive results as to receive USFDA orphan-drug approval in December 2015

Bicycle Therapeutics (Phase I clinical trial) utilize a bicyclic peptide: a synthetic, conformationally constrained peptide which includes an intramolecular linkage between its termini or amino acid side chains, with conjugated toxin DM1, to create their latest drug candidate BT1718. Bicycle therapeutics is also exploring the use of bicyclic peptides outside of oncology, with a billion-dollar AstraZeneca partnership to develop respiratory and cardio-metabolic therapeutics.

MicroQuin, an international start-up with cancer-targeting CPP technology, is in the final stages of preclinical studies and validation. Their proof-of-concept Targeted-Doxorubicin (Tardoxocin) has demonstrated an improvement in efficacy by up to $30 \mathrm{X}$ and a reduction in toxicity by up to $20 \mathrm{X}$ across a range of cancers including breast, lung, ovarian, and prostate. With simple chemistry, doxorubicin can potentially be exchanged for any other anti-cancer agent treating a range of different cancers and their subtypes, offering pharmaceutical companies the substantial opportunity to diversify their pipeline or secure technology coming out-of-patent.

\section{Creating Next Generation Targeted Oncology Treatments}

As outlined previously there have been several approaches to create targeted cancer therapies which have been hindered by the complex, heterogenous nature of cancers, their ability to evade or overcome a therapy as well as lack of understanding of the body's immune response [12-16]. Despite some early stage set backs, CPPs seemingly offer a superior mode of intracellular delivery, with little or no immune response and the potential for drastically fewer therapeutic side effects owing to their greater targeted nature. Furthermore, resistance and secondary cancers from immune-resistant cancer cell clones were shown to be less likely to develop [17]. The mode of action is reliant on universally expressed proteins in cancer, and efficacy will be constant regardless of tumor size, reducing remission rates.

\section{Concluding Remarks}

CPPs have the potential to revolutionize the future of cancer therapeutics, offering patients drastically improved quality of life, fewer side effects and better prognosis, and 'Big Pharma' the opportunity for big returns. Even the most toxic of chemotherapies, saved for those in the latest of stages of cancer, could be reinvigorated with greatly reduced toxicity for use in early stage cancers. Despite the developments made with CPPs towards the end of the $20^{\text {th }}$ century, there are currently no CPP based drugs on the market. The predominant reason is the difficult nature of discovering candidates with great enough selectivity towards tumors. A possible concern with CPPs is their short serum half-life as a result of proteolysis, however, with the incorporation of D-amino acids instead of the body's natural L-amino acids, or the production of a biomimetic, proteolysis can be minimized, and pharmacodynamics made more favorable. Pharmaceutical companies' most debilitating obstacles loss of exclusivity or patent expiration - can be postponed with the creation of a new Investigational New Drug (IND) for drugs conjugated to CPPs.

\section{Conflict of Interest}

This paper was written with financial support from MicroQuin. MicroQuin has a CPP technology which is stated in this paper.

\section{References}

1. Frankel A, Pabo C (1988) Cellular uptake of the tat protein from human immunodeficiency virus. Cell 55(6): 1189-1193.

2. Green M, Loewenstein P (1988) Autonomous functional domains of chemically synthesized human immunodeficiency virus that trans-activator protein. Cell 55(6): 1179-1188. 
3. Joliot A, Pernelle C, Deagostini Bazin H, Prochiantz A (1991) Antennapedia homeobox peptide regulates neural morphogenesis. Proceedings of the National Academy of Sciences 88(5): 1864-1868.

4. Derossi D, Joliot A, Chassaing G, Prochiantz A (1994) The Third helix of the antennapedia homeodomain translocates through biological membranes. Journal of Biological Chemistry 269(14): 10444-10450.

5. Fawell S, Seery J, Daikh Y, Moore C, Chen LL, et al. (1994) Tat mediated delivery of heterologous proteins into cells. Cell Biology, pp. 9166491668.

6. Vivès E, Schmidt J, Pèlegrin A (2008) Cell-penetrating and cell-targeting peptides in drug delivery. Biochimica et Biophysica Acta (BBA) 1786(2): 126-138.

7. Park J, Ryu J, Kim KA, Lee HJ, Bahn JH, et al. (2002) Mutational analysis of a human immunodeficiency virus type 1 Tat protein transduction domain which is required for delivery of an exogenous protein into mammalian cells. Journal of General Virology 83(Pt 5): 1173-1181.

8. Guidotti G, Brambilla L, Rossi D (2017) Cell-penetrating peptides: from basic research to clinics. Trends in Pharmacological Sciences 38(4): 406424.

9. Heitz F, Morris M, Divita G (2009) Twenty years of cell-penetrating peptides: From molecular mechanisms to therapeutics. British Journal of Pharmacology 157(2): 195-206.

10. Zhang YE, Wang JN, Tang JM, Guo LY, Yang JY, et al. (2009) In Vivo protein transduction: Delivery of PEP-1-SOD1 fusion protein into myocardium efficiently protects against ischemic insult. Molecules and Cells 27(2): 159-166.

11. Borrelli A, Tornesello A, Tornesello M, Buonaguro F (2018) Cell penetrating peptides as molecular carriers for anti-cancer agents. Molecules 23(2): 295

12. Ke X, Shen L (2017) Molecular targeted therapy of cancer: The progress and future prospect. Frontiers in Laboratory Medicine 1(2): 69-75.

13. Kim D, Shin K, Kwon S, Hyeon T (2018) Synthesis and biomedical applications of multifunctional nanoparticles. Advanced Materials.

14. Saleem J, Wang L, Chen C (2018) Carbon-based nanomaterials for cancer therapy via targeting tumor microenvironment. Adv Healthc Mater 2: e1800525.

15. Shao J, Fan W, Ma B, Wu Y (2016) Breast cancer stem cells expressing different stem cell markers exhibit distinct biological characteristics. Molecular Medicine Reports 14(6): 4991-4998.

16. Sheppard S, Joana G, Anna M, Anastasia Maria Z, Hiromi K, et al. (2017) The immunoreceptor NKG2D promotes tumor growth in a model of hepatocellular carcinoma. Nature Communications.

17. Pitt J (2016) Resistance mechanisms to immune-checkpoint blockade in cancer: Tumor-intrinsic and -extrinsic factors. Immunity 44(6): 318325.

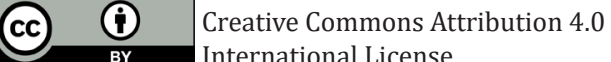

International License

For possible submissions Click Here
Submit Article

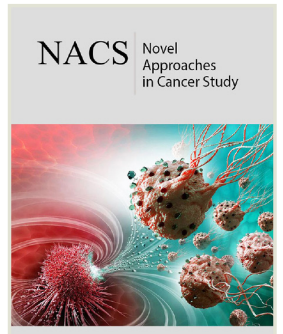

\section{Novel Approaches in Cancer Study}

\section{Benefits of Publishing with us}

- High-level peer review and editorial services

- Freely accessible online immediately upon publication

- Authors retain the copyright to their work

- Licensing it under a Creative Commons license

- Visibility through different online platforms 